\title{
Concurrent and Predictive Validity of the Adolescent Drug Abuse Diagno- sis (ADAD)
}

\author{
Josefine Börjesson and Helene Ybrandt*
}

Department of Psychology, Umeå University, SE-90187 Umeå, Sweden

\begin{abstract}
The concurrent and predictive validity of the Adolescent Drug Abuse Diagnosis (ADAD) in the Psychological status and problem area was examined for two adolescent groups: a non-clinical population of 121 Swedish adolescents (62 girls and 59 boys) aged 15 to 17 years and a clinical population of 31 adolescents (14 girls and 17 boys) aged 12 to 19 years detained in special youth homes. Concurrent validity was demonstrated by significant correlations between the ADAD, Youth Self Report (YSR) and Beck Depression Inventory (BDI) scores. Findings regarding the predictive validity of ADAD show moderate associations with YSR, BDI and DICA problem ratings. The findings suggest that for clinical practice the ADAD Psychological status and problem area may be an appropriate assessment tool for measurement of current psychological problems. The utility obtained by making decisions using the test is substantial.
\end{abstract}

Keywords: Adolescent Drug Abuse Diagnosis, ADAD, adolescents, concurrent validity, predictive validity, psychological health.

The combination of mental illnesses such as depression and anxiety and substance abuse is common in the group of adolescents with antisocial behavior problems [1]. Studies show that more than half of young persons with a substance abuse diagnosis also have a diagnosable mental illness [2]. Treatment is assessed as either required or recommended for 60 percent of those detained in special youth homes under the Swedish Care of Young Persons Act. Approximately 40 percent of the adolescents themselves claim that they wish to get help for psychological problems [3]. In the light of this prevalence of the need for treatment, it seems important to have valid instruments that can assess an adolescent's state of health and contribute to an appropriate focus of the treatment, especially when dual diagnoses are available. It is also important for treatment planning and predicting treatment outcome to know the benefit obtained by making decisions using the assessment instrument.

The Adolescent Drug Abuse Diagnosis (ADAD) interview [4] is one of the instruments that have been used for screening for mental health problems in adolescents with antisocial behavior problems. Besides investigating the adolescent's psychological health status, the ADAD interview evaluates problems in eight life areas, namely medical, school, employment, social, family, legal, alcohol and drugs. Problems in these areas are thought to be related to substance use problems in adolescence. Ybrandt [5] found that for those aged between 12 and 18 years, the ADAD identified the general risk factors for alcohol use as leisure and peer problems, problems associated with family background and

*Address correspondence to this author at the Department of Psychology, Umeå University, SE-90187 Umeå, Sweden; Tel: +46 90 786; 6 197;

Fax: +4690786 6695; E-mail: helene.ybrandt@psy.umu.se relationships, and criminal behavior. It was also found that the ADAD problem areas seem to be most useful as prognostic indicators of treatment outcome for adolescents with antisocial problems who are under 18 years of age. These results suggest that drug abuse treatment planning should focus on altering the predisposing factors that exist in these domains for example the adolescent having drug-using friends with deviant behavior, the adolescent's own antisocial behavior and engagement in illegal activities, low bonding to the family, conflicting behavior towards parents, and low levels of support from the parents.

A recent study of the psychometric properties of the psychological status and problem area of the Swedish version of the ADAD shows good inter-rater reliability and satisfactory concept validity [6]. However, the concurrent and predictive validity of the Psychological status and problem area of the Swedish version of ADAD has not previously been examined. It is therefore important to find out which types of information about adolescent mental health problems are revealed by the different measures in the Psychological status and problem area, and whether it is possible to predict future mental health behavior based on these subscores. It is also important to determine whether the subscores of the instrument reflect mainly internalizing or externalizing of problems, or whether they offer a total picture of the adolescent's mental health problems.

Each of ADAD life areas produces four different measures: the adolescent's ratings (AR), the interviewer severity ratings (ISR), the critical items (CI), and the composite score (CS). The psychological status and problem area also includes a psychological status and problem checklist (PPCL). The interviewer severity ratings take into account the adolescent's rating of his or her need for help within the 
area. The critical items are important items affecting the interviewer's severity ratings that are recommended for assessment at any evaluation following admission or pretreatment. The CI is utilized in calculating the CS, but other items are also included because they yield clinically useful information for ongoing treatment planning [7].

In the present study the measurements obtained using the ADAD Psychological status and problem area are evaluated in relation to the Diagnostic and Statistical Manual of Mental Disorders (DICA-R) [8]. Two other widely used instruments $[9,10]$ were also used as references: the Beck Depression Inventory (BDI) [11] for assessing depression and common psychiatric problems in adolescent populations, and the Youth Self Report (YSR) [9]. The BDI and YSR instruments are used in research and clinical practice and have been translated into several languages $[9,10]$. The validity of the YSR has been explored and upheld by several international studies [12-16] . A Swedish study [17] of the YSR found that both internalizing and externalizing problems in school-age adolescents correlate with the BDI (Beck Depression Inventory) [11].

Several investigations have also demonstrated the psychometric properties of BDI in comparison with other selfrating tests of depression [18,19]. Beck, Steer and Garbin [20] showed excellent validity. Canals, Blade, Carbajo, and Domenech-Llaberia [21] found the instrument to be useful in differentiating between normal and depressed adolescents in the general population.

Bolognini et al. [22] correlated scores on the BDI with scores in the ADAD Psychological status and problem area. The correlation coefficient between the CS and the BDI was .69 , and that between the ISR and the BDI was .52. They also found that the BDI score was correlated with the psychological items "experienced serious depression occurring during the last 30 days" and "experienced serious thoughts of suicide occurring during the last 30 days".

In the present study the concurrent validity of the ADAD Psychological status and problem area was assessed through correlations with the YSR and the BDI in a group of normal adolescents, on the assumption that the measures included in the ADAD's Psychological status and problem area should be associated with the BDI and YSR scales. The predictive validity of the ADAD's Psychological status and problem area was examined in both the normal group of adolescents and in a group of adolescents with antisocial behavior problems. It was anticipated that the stability of the measures would be poor as the ADAD is intended primarily as an instrument to mirror the current state of the adolescent. A follow-up interval ranging from one to three years was used.

In short, we tested two hypotheses regarding the validity of the ADAD Psychological status and problem area. First, we hypothesized that the problem area should correlate positively and significantly with similar measures. We expected that the CS and the ISR would show the strongest correlation with the BDI and the YSR, in keeping with the results of Bolognini et al. [22]. Second, we expected low correlations between scores on the ADAD Psychological status and problem area and those on follow-up instruments.

\section{METHOD}

\section{Participants}

The normal adolescent group consisted of 121 Caucasian adolescents ( 62 girls and 59 boys) aged 15 to 17 years ( $M=$ $16.0, \mathrm{SD}=.82$ ). The adolescents were randomly selected from a register of all adolescents in a town in the north of Sweden (111.000 inhabitants) to obtain an equal number of boys and girls in the three age groups 15, 16 and 17.

The adolescent group with antisocial and psychiatric problems was part of a larger study of treatment effects called the Antisocial Adolescence Project at the University of Umeå [23]. The project was reviewed and approved by the Swedish regional ethical board. The group consisted of 31 adolescents (14 girls and 17 boys) aged 12 to 19 years ( $\mathrm{M}=$ $15.2, \mathrm{SD}=1.76)$. A higher mean age was found for the adolescents in the normal group $(\mathrm{t}(33.38)=2.48, p<.05)$.

In the normal adolescent group $68 \%$ lived with two biological parents, which is slightly more than the average in Sweden for the age groups 15-17 (approximately $60 \%$ ) [24], while $25 \%$ lived with a single parent. Significant group differences were found with more adolescents in the normal group compared to the adolescent group with antisocial problems living with both parents $\left(X^{2}=44.32, \mathrm{df}=6, p<\right.$ .001 ) and more adolescents in the normal group have parents that are employed $\left(X^{2}=46.52, \mathrm{df}=3, p<.001\right)$. In the group of adolescents with antisocial problems, it was far more common for the adolescent to be living with a single parent $(53 \%)$. Unemployed parents were also more common in the group of antisocial adolescents. This pattern of living arrangements and work status mirrors that for adolescents in custody in Sweden [3]. Demographics and other relevant characteristics for the normal and antisocial adolescent groups are summarized in Table $\mathbf{1}$.

\section{PROCEDURE}

\section{Normal Adolescent Group}

Baseline assessment. The participants were initially contacted by letter with a request to participate in the study. Once replies had been received by the Department of Psychology, the interviewers called the adolescents to set up a time and place for the interview. ADAD data were then obtained from each adolescent during the face-to-face structured interview. The YSR and BDI questionnaires were filled out at the end of the session. The adolescents received a cinema voucher as compensation. The interviewing staff consisted of five persons; four psychology students who were close to completing their studies and one experienced clinical psychologist. All the interviewers were women and all participated in a two-day training course on how to conduct an ADAD interview. Each interviewer had to conduct two approved test interviews. The course was given by a psychologist with extensive experience of ADAD interviews.

Follow-up assessment. One year after the initial administration of the ADAD interview, sixty of the normal adolescents were contacted again and asked whether they wanted to participate in an additional study. Fifty positive answers were received. The same interviewers as in the baseline 
Table 1. Demographics and Other Characteristics of the Normal and Antisocial Adolescent Groups

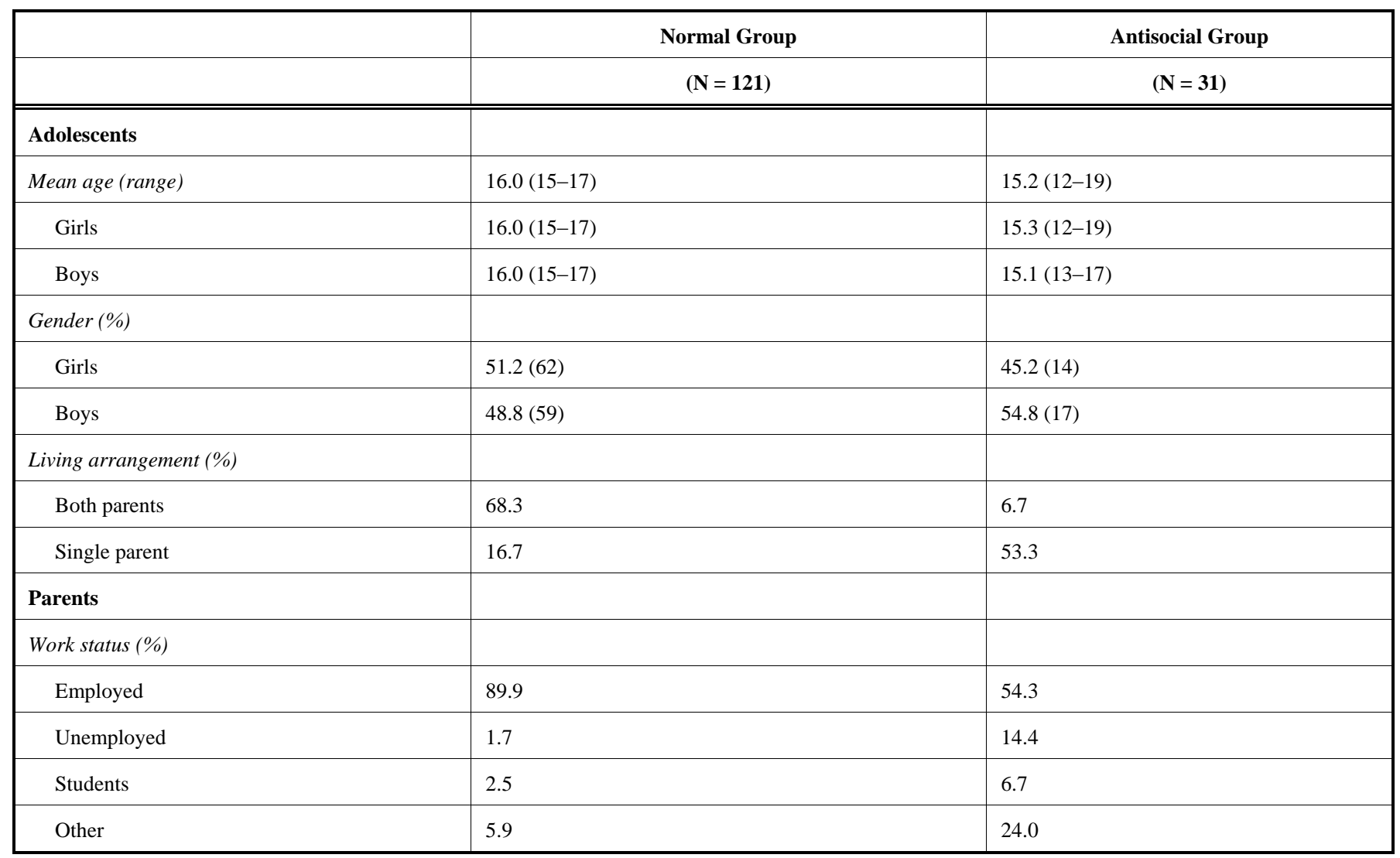

assessment conducted the Diagnostic Interview for Children and Adolescents (DICA).

\section{Antisocial Adolescent Group}

Baseline assessment. The antisocial group of participants received information about the project from the staff at the special youth homes and the leaders of the project. Their participation was voluntary and contingent upon the consent of both their parents and themselves. The adolescents received a closed envelope with questionnaires including the YSR and BDI and returned the envelope to the project leader by mail. A cinema ticket was given in return. The ADAD interview was administered from a database that was organized and made available by the National Board of Institutional Care. The attrition consisted of those who chose not to take part, had not received information about the project, or did not manage to fill in the questionnaires.

Follow-up assessment. Follow-up assessment included the YSR and the BDI administered after a three-year period.

Accordingly, data in this study came from two different study conditions which had different administration for the follow-up assessment (one-year respective three year follow up) and different assessment tools used at follow up.

\section{MEASURES}

The ADAD is a structured interview containing 150 items that evaluate a youth's problems in nine life areas [4].
In this study only the Psychological status and problem area was considered using four different measures: the ISR, CS, PPCL, and CI. The Swedish version of the ADAD closely replicates the American version [25].

The ISR is the interviewer's rating of the adolescent's need for help for psychological and emotional problems based on the answers to items in the subscale, as well as the subject's own rating of their degree of worry about these problems and their need for help. The ISR is filled out after the interview and scored for problem severity on a 10-point scale ranging from no real problem $(0-1)$ to extreme problems (8-9).

The CS is a measure of the severity of the adolescent's problem status at the time and can be used in studies of the effects of intervention and treatment programs to assess changes in problem severity over time. The construction of the CS makes it more suitable for evaluating changes than the ISR since it is independent of the interviewer's clinical judgment of the "severity" of the problems in each problem area, which includes the adolescent's self-ratings of severity and need for help. The CS is calculated on the basis of the sub-scores in the psychological area.

The PPCL consists of 49 items on common adolescent psychological and emotional reactions and symptoms and includes an assessment of lifetime psychiatric status in terms of the most common diagnostic categories such as anxiety, depression, and hallucinations. The number of suicide attempts was excluded, as well as items reflecting the last 30 days. The answers were rated with $0=$ no and $1=$ yes. Ten 
items are marked as critical in the PPCL. The interviewer uses these items as a basis for evaluating the severity of the adolescent's problems. The CI is a summary of the critical items included in the psychological area. Thus, two of the Psychological status and problem area are subjective evaluations (ISR and PPCL) and two are considered to offer more "objective" views of the problem severity (CI and CS).

YSR. The YSR [9] is a standardized self-report questionnaire for adolescents aged 11 to 18 years. The problem section contains nine subscales with a total of 112 items. The nine subscales are Withdrawn, Somatic Complaints, Anxious/Depressed, Social Problems, Thought Problems, Attention Problems, Delinquent Rule-Breaking Behaviors, Aggressive Behaviors, and Self-destructive/Identity Problems. The subscales Withdrawn, Somatic Complaints and Anxious/Depressed together comprise the broad internalizing dimension, whereas Delinquent Rule-Breaking Behaviors and Aggressive Behaviors together constitute the externalizing dimension. The youth is asked to rate how well the items (e.g., I am mean to others; I am shy; I feel that I have to be perfect) describe himself or herself now or over the last six months. The adolescent is asked to rate each item on a threepoint scale; $0=$ not true, $1=$ somewhat or sometimes true, and $2=$ very true or often true.

The YSR has been evaluated on 1.057 American children aged 11 to 18 years and the validity has been found to be acceptable. Test-retest reliability ranged from .47 to .79 and internal consistency ranged from .71 to .95 [9]. The YSR has been translated into Swedish and back to English to ensure congruence with the original. In a recent Swedish study the internal consistency was found to be between .51 and .70 for the narrow-band syndromes and was found to be good for the two broadband dimensions Internalizing/ Externalizing [26]. Several international studies support the reliability of the YSR $[12,9]$. In the present study, the total score and the two internalizing/externalizing dimensions of YSR were used. The measures were the mean values of the raw scores on these dimensions.

BDI. The BDI [11] consists of 21 groups of symptoms and attitudes related to the cognitive, behavioral, affective, and somatic components of depression such as feelings of guilt, pessimism, self-contempt, changes in appetite and sleeping patterns, and thoughts of suicide. Respondents are offered four statements rated from 0 to 3 in terms of severity and are asked to indicate which statement best describes how they have felt in the last week. The scores are evaluated in relation to cut-off scores. For no or minimal depression the score is set to $<10$. for mild to moderate depression it is set to $10-16$, for moderate to severe depression to $17-29$, and for severe depression > 30 [20]. The psychometric properties of BDI have been shown to be excellent. The internal consistency has been confirmed by several studies in psychiatric and nonpsychiatric samples. Most of researchers report alpha coefficients that are on average higher than 0.75 . Studies of its concurrent validity with other self-rating scales report moderate to high correlation coefficients with mean coefficients ranging from 0.58 to 0.79 . Studies of its differential validity show that the BDI reliably discriminates between depressives and non-depressives [27].

DICA. The Swedish translation of the Diagnostic Interview for Children and Adolescents (DICA-R) was used to determine the incidence of problems. DICA-R is a structured interview based on the DSM-III-R, the Diagnostic and Statistical Manual of Mental Disorders [8]. It has been found to have satisfactory test-retest and inter-rater reliability and good concurrent and discriminate validity [28,29]. Testretest reliability has been good ranging between .76 and .90 [30]. DICA-based diagnostic scores correspond well with symptom checklist scores $[31,32]$ and other diagnostic interview scores [33,34].

\section{Statistical Analyses}

Statistically significant differences between the ADAD, BDI and YSR for the total group of normal and antisocial adolescents were determined using the independent t-test.

The concurrent validity of the ADAD Psychological status and problem area was evaluated using correlations and by comparing the mean scores of the groups. The predictive validity of the ADAD Psychological status and problem area was evaluated by exploring correlations between the

Table 2. Mean, Standard Deviations, and Ranges for ADAD Measures ISR, CS, PPCL and CI; and BDI and YSR (total, Internalizing and Externalizing). Scores for the Normal and Antisocial Adolescent Group

\begin{tabular}{|l|c|c|c|c|}
\hline \multirow{2}{*}{ Measures } & \multicolumn{2}{c|}{ Normal Group } & \multicolumn{2}{c|}{ Antisocial Group } \\
\hline \hline ISR & $(N=121)$ & Range & $4=31)$ & Range \\
\hline CS & $.88(1.42)$ & $0-7$ & $12.62(11.79)$ & $0-9$ \\
\hline PPCL & $4.20(4.16)$ & $0-20$ & $15.31(9.19)$ & $2.74(2.52)$ \\
\hline CI & $7.24(5.83)$ & $0-28$ & $17.62(17.27)$ & $1-41$ \\
\hline BDI score & $.79(1.34)$ & $0-6$ & $54.50(31.48)$ & $0-60$ \\
\hline YSR total & $4.08(4.31)$ & $0-23$ & $16.22(12.35)$ & $13-146$ \\
\hline Internalizing & $27.50(14.44)$ & $3-71$ & $22.96(12.00)$ & $1-48$ \\
\hline Externalizing & $7.25(5.76)$ & $0-22$ & $2-37$ & $5-56$ \\
\hline
\end{tabular}


subscores of the ADAD and the BDI, YSR and DICA scores.

Data were analyzed with SPSS (Statistical Package for the Social Sciences) version 18.0. The level of significance was $p<.05$ (two-tailed).

\section{RESULTS}

\section{Descriptive Statistics}

Table 2 presents the mean scores and standard deviations for the normal and antisocial groups for the ADAD, BDI, and YSR measures. Significant group differences were found on ADAD ISR t $(35)=8.18, \mathrm{p}<.01$; ADAD CS, $\mathrm{t}(30)=$ $3.79, \mathrm{p}<.01$; ADAD PPCL, $\mathrm{t}(29)=4.52$, $\mathrm{p}<.01$; and ADAD CI, $\mathrm{t}(34)=4.16, \mathrm{p}<.01$. The YSR total score was $\mathrm{t}$ $(27)=4.27, \mathrm{p}<.01$, YSR internalizing score $\mathrm{t}(29)=3.68, \mathrm{p}$ $<.01$, YSR externalizing score, $\mathrm{t}(29)=4.36, \mathrm{p}<.01$. The BDI score was $\mathrm{t}(29)=4.19, \mathrm{p}<.01$, with more depressive and psychological problems for antisocial adolescents. The YSR values in the normal adolescent group fell within the normal range, but were slightly lower than the findings in a Swedish normative study [26]. The means for the total normal sample on the BDI were in range indicating no depression or minimal depression (score $<0$ ). The depressed adolescents $(8 \%$ of the total) scored in the range of moderate depression.

\section{Concurrent Validity of the ADAD Scores on Psychologi- cal Status and Problem Area}

To assess concurrent validity, correlations between the ADAD psychological subscores and the YSR and BDI scores of the normal adolescents were calculated. Table $\mathbf{3}$ shows that the ADAD measures were significantly correlated with both the YSR (ranging from .38 to .80) and BDI measures (ranging from .59 to .70). There was high correlation for the PPCL (ranging from .51 to .80) and total problem severity, internalized problems and depression.

ADAD Psychological status and problem area predictors of YSR total, internalizing, externalizing, and BDI

\section{Predictive Validity of the ADAD Psychological Status and Problem Area}

To assess predictive validity, correlations were computed to analyze the strength of the relationship between the ADAD psychological subscores and the YSR and BDI scores in a three-year follow-up test for the group of antisocial adolescents, and between the ADAD psychological subscores and DICA scores in a one-year follow-up for the normal adolescent group. The results are shown in Table 4.

The ADAD measures show low to moderate associations to the YSR (ranging from .37 to .49), BDI (ranging from .33 to .44) and DICA total (ranging from .46 to .55) and DICA serious depression rating (ranging from .26 to .43 ).

\section{DISCUSSION}

The purpose of this study was to investigate both the concurrent and predictive validity of the ADAD Psychological status and problem area. As expected, it was found that the ADAD psychological status and problem area has good concurrent validity for normal adolescents, and low to moderate predictive validity for normal and antisocial adolescent groups.

The correlations between criteria measures can be used to establish the usefulness of the ADAD Psychological status and problem area in distinguishing psychological problems

Table 3. Correlations between ADAD (ISR, CS, PPCL, CI) and YSR and BDI in Normal Adolescents

\begin{tabular}{|l|c|c|c|c|}
\hline & YSR (Tot) & YSR (Ext) & YSR (Int) & BDI score \\
\hline \hline ISR & $.60^{* *}$ & $.44^{* *}$ & $.58^{* *}$ & $.62^{* *}$ \\
\hline CS & $.62^{* *}$ & $.38^{* *}$ & $.59^{* *}$ & $.59^{* *}$ \\
\hline PPCL & $.80^{* *}$ & $.51^{* *}$ & $.77^{* *}$ & $.70^{* *}$ \\
\hline CI & $.65^{* *}$ & $.51^{* *}$ & $.54^{* *}$ & $.61^{* *}$ \\
\hline
\end{tabular}

Note. $* \mathrm{p}<.05 * * \mathrm{p}<.01$

Table 4. Correlations between ADAD (ISR, CS, PPCL, CI,) and YSR and BDI (3-year Follow-up) in Antisocial Adolescents and DICA (One-Year Follow-up) in Normal Adolescents

\begin{tabular}{|c|c|c|c|c|}
\hline & \multicolumn{2}{|c|}{ Antisocial adolescents $(\mathbf{N}=\mathbf{3 1}$ ) } & \multicolumn{2}{c|}{ Normal adolescents (N= 50) } \\
\hline & YSR (Total) & BDI score & DICA (Total) & DICA (Ser. Depr.) \\
\hline \hline & & & $.55^{* *}$ & $.43^{* *}$ \\
\hline ISR & .40 & $.37^{*}$ & $.46^{* *}$ & .26 \\
\hline CS & .38 & .37 & $.53^{* *}$ & $.30^{*}$ \\
\hline PPCL & $.49^{*}$ & $.44^{*}$ & $.54^{* *}$ & .28 \\
\hline
\end{tabular}

Note. $* \mathrm{p}<.05 * * \mathrm{p}<.01$ 
in adolescent groups. Results show that the ADAD psychological status and problem submeasures correlated significantly with the YSR and BDI scores in the normal adolescent group. Using Cohen's [35] description of small $(r=$ $.10)$, moderate $(r=.30)$, and strong $(r=.50)$ correlation effect sizes, the ADAD Psychological status and problem area was found to have moderate to strong associations with the YSR and BDI scales, as had been expected. These results are consistent with the findings of Bolognini et al. [22], who reported that the BDI scores were correlated with the ADAD Psychological status and problem area. Furthermore, ADAD psychological status and problem subscores were significantly associated with both internalizing and externalizing problems. Stronger correlations were found between the ADAD psychological status and problem subscores and YSR internalizing problems as compared to YSR externalizing problems. It seems that the ADAD psychological status and problem subscores consist mainly of questions dealing with internalizing problems. The strongest associations were found between PPCL scores and YSR and BDI scores. Moreover, the correlations between ADAD psychological subscores and YSR (total) score and BDI score were comparable. Our findings support the concurrent validity of the ADAD psychological subscale and the assumption that the subscale serves as a good screening measure for psychological problems in normal adolescents. It is important to verify the concurrent validity in a group of adolescents with antisocial problems in the same way. It is also important to consider the result found in this study with regard to internalizing problems, which were mainly evaluated using the ADAD. This instrument is perhaps less useful in summarizing the unique problems in groups of adolescents who have antisocial problems with a more externalizing character. Perhaps questions should be added describing externalizing problems such as aggression and delinquent rule-breaking behavior in order to make the instrument more suitable for that group of adolescents.

Another way to calculate concurrent validity is to compare normal adolescent groups and antisocial adolescent groups using the means and standard deviations for each measure (Table 2). The analyses demonstrated significant differences between the means of the groups in the ADAD Psychological status and problem area, as well as the YSR and BDI scales. Thus this calculation further supports the concurrent validity of the ADAD Psychological status and problem area.

According to Kline [36] a correlation around .30 or .40 should be seen as evidence for the predictive validity of a test. Our correlations show a moderate correlation together with evidence for strong correlations between the ADAD and DICA total severity score.

The sample size in this study is relatively small. However, Schmidt, Hunter, \& Urry [37], found that for sample sizes between 30 and 50, a predictor that has an acceptable validity level, as in our case, is likely to have acceptable validity levels only $25 \%$ to $35 \%$ of the time. A sample of 200 or more may be needed to reflect validity levels of population data accurately at least $90 \%$ of the time. According to these authors our results should be reduced to around .25 to .35 . This predictive validity gives fairly good support for the efficacy of the ADAD Psychological status and problem area, making it a relatively good instrument for predicting future mental health. Thus the utility obtained by making decisions using the ADAD instrument is quite substantial when using the ISR and PPCL with both normal and antisocial adolescent groups. However, additional studies are require before making general conclusions of the efficacy of the ADAD predicting future mental health, overcoming the present study limitations e.g. the small adolescent groups, the assessment differences between the adolescent groups (design and instruments) and time points, possible interferences of other important factors and the correlation not proving causal relations.

In summary, for clinical practice and research purposes the ADAD Psychological status and problem area may be an appropriate assessment tool with moderate concurrent and predictive validity in the measurement of psychological problems.

\section{CONFLICT OF INTEREST}

The authors confirm that this article content has no conflicts of interest.

\section{ACKNOWLEDGEMENT}

None declared.

\section{REFERENCES}

[1] Drerup LC, Croysdale A, Hoffmann NG. Patterns of behavioral health conditions among adolescents in a juvenile justice system. Prof Psychol-Res Pr 2008; 39(2): 122-8

[2] Amstrong TD, Costello EJ. Community studies on adolescent substance use, abuse, or dependence and psychiatry comorbidity. J Consult Clin Psych 2002; 70: 1224-39.

[3] SiS. (2010). Ungdomar inskrivna på SiS särskilda ungdomshem under 2009. En sammanställning av ADAD inskrivningsintervju. Allmän SiS-rapport 2010:8 [Adolescents detained at SiS special youth homes 2009. An overview of ADAD interviews. Annual report ADAD 2010:8]. Sweden: Author.

[4] Friedman AS, Utada A. A method for diagnosing and planning the treatment of adolescent drug abusers (The Adolescent Drug Abuse Diagnosis (ADAD) instrument). J Drug Edu 1989; 19(4): 285-312.

[5] Ybrandt H. Risky alcohol use, peer and family relationships, and legal involvement in adolescents with antisocial problems. J Drug Edu 2010; 40(3): 243-62.

[6] Börjesson J, Armelius B-Å, Östgård-Ybrandt H. The psychometric properties of the Swedish version of Adolescent Drug Abuse Diagnosis (ADAD). Nord J Psychiat 2007; 61(3): 225-32

[7] Ybrandt H, Börjesson J, Armelius B-A. The adolescent drug abuse diagnosis composite scores in Swedish normal and antisocial adolescents. Subst Use Misuse 2008; 43: 1411-23.

[8] Herjanic B, Reich W. Development of a structured psychiatric interview for children: Agreement between child and parent on individual symptoms J Abnorm Child Psychol 1982; 10 (3): 307-24.

[9] Achenbach TM. Manual for the Youth Self-report and 1991 profile. Burlington: University of Vermont 1991.

[10] Byrne BM, Baron P, Larsson B, Melin L. Measuring depression for Swedish nonclinical adolescents: factorial validity and equivalence of the beck depression inventory across gender. Scand J Psychol 1996; 37: 37-45.

[11] Beck AT, Ward CH, Mendelson M, Mock J, Erbaugh J. An inventory for measuring depression. Arch Gen Psychiat 1961; 4: 53-63.

[12] DeFrancesco JJ, Armstrong SS, Russolillo PJ. On the reliability of the Youth Self-Report. Psychol Rep 1996; 79: 322.

[13] Ritter DR. Adolescent suicide: social competence and problem behaviour of youth at high risk and low risk for suicide. School Psychol Rev 1990; 19: 83-95. 
[14] Slobodskaya HR. Competence, emotional, and behavioral problems in Russian adolescents. Eur Child Adoles Psychiatr 1999; 8: 17380.

[15] Song L, Singh J, Singer M. The youth self-report inventory: a study of its measurement fidelity. Psychol Assess 1994; 6(3): 236-45.

[16] Steinhausen HC, Metzke CW. Youth self-report of behavioral and emotional problems in a Swiss epidemiological study. J Youth Adolesc 1998; 27: 429-41.

[17] Lindeberg L, Wargert G, Bremberg S. Mental health at the age of twelve. Stockholm: SLL 1998: 2.

[18] Ambrosini PJ, Metz C, Bianchi MD, Rabinovich H, Undie A. Concurrent validity and psychometrics properties of the beck depression inventory in outpatient adolescents. J Am Acad Child Adolesc Psychiatr 1991; 30 (1): 51-7.

[19] Kendall SPC, Hollon SD, Beck AT, Hammen CL, Ingram RE. Issues and recommendations regarding use of the beck depression inventory. Cogn Ther Res 1987; 11: 289-99.

[20] Beck AT, Steer RA, Garbin MG. Psychometric properties of the Beck Depression Inventory: Twenty-five years of evaluation. Clin Psychol Rev 1998; 8(1): 77-100.

[21] Canals J, Blade J, Carbajo G, Domènech-Llaberia. The beck depression inventory: psychometric characteristics and usefulness in nonclinical adolescents. Eur J Psychol Assess 2001; 17(1): 63-8.

[22] Bolognini M, Plancherel B, Laget J, et al. Evaluation of the Adolescent Drug Abuse Diagnosis instrument in a Swiss sample of drug abusers. Addiction 2001; 96: 1477-84.

[23] Armelius B- $\AA$, Hägglöf B. Psychological problems among adolescents with antisocial behavior. Umeå, Sweden: University of Umeå 1998.

[24] Statistics Sweden. Stockholm: SCB 2010.

[25] Söderholm Carpelan K, Hermodsson A. ADAD and the development of a documentation system. Nordisk Socialt Arbeid 2004; 24(2): 110-23.

[26] Broberg AG, Ekeroth K, Gustafsson PA, et al. Self-reported competencies and problems among Swedish adolescents: a normative study of the YSR. Eur Child Adoles Psychiatr 2001; 10(3): 186-93.
[27] Richter P, Werner J, Heerlein A, Kraus A, Sauer, H. On the validity of the beck depression inventory. Psychopathology 1998; 31: 1608.

[28] Herjanic B, Reich W. Development of a structured psychiatric interview for children: Agreement between child and parent on individual symptoms. J Abnorm Child Psychol 1997; 25: 21-31.

[29] Reich W. Diagnostic interview for children and adolescents (DICA). J Am Acad Child Adolesc Psychiatry 2000; 39(1): 59-66.

[30] Bartlett JA, Schleifer SJ, Johnson RL, Keller SE. Depression in inner city adolescents attending an adolescent medicine clinic. J Adolescent Health 1991; 12: 316-8.

[31] Cerel J, Fristad MA. Scaling structured interview data: A comparison of two methods. J Am Acad Child Adolescent Psychiatr 2001; 40: 341-6.

[32] Sprafkin J, Gadow KD, Salisbury H, Schneider J, Loney J. Further evidence of reliability and validity of the Child Symptom Inventory-4: parent checklist in clinically referred boys. J Clin Child Adolescent Psychol 2002; 31: 513-24.

[33] Teare M, Fristad MA, Weller EB, Weller RA, Salmon P. Study I: Development and criterion validity of the children's interview for psychiatric syndromes (ChIPS). J Child Adolescent Psychopharmacol 1998a; 8: 205-11.

[34] Teare M, Fristad MA, Weller EB, Weller RA, Salmon P. Study II: Concurrent validity of the DSM-III-R Children's Interview for Psychiatric Syndromes (ChIPS). J Child Adolescent Psychopharmacol 1998b; 8: 213-9.

[35] Cohen J. A power primer. Psychol Bull 1992; 112: 155-9.

[36] Kline P. Handbook of psychological testing. London: Routledge 2000.

[37] Schmidt FL, Hunter JE, Urry VW. Statistical power in criterionrelated validity studies. In: Introduction to classical and modern test theory. Crocker L, Algina J, Eds. USA: Cengage Learning 1976; pp 225-6.

Received: July 26, 2012

Revised: October 01, 2012

Accepted: October 01, 2012

(C) Börjesson and Ybrandt; Licensee Bentham Open.

This is an open access article licensed under the terms of the Creative Commons Attribution Non-Commercial License (http://creativecommons.org/licenses/ by-nc/3.0/) which permits unrestricted, non-commercial use, distribution and reproduction in any medium, provided the work is properly cited. 